\title{
UTILIZAÇÃO DO CULTIVO IN VITRO DE FOLÍCULOS PRÉ-ANTRAIS SUÍNOS INCLUSOS EM TECIDO OVARIANO (IN SITU) COMO MODELO DE AVALIAÇÃO DA EFICIÊNCIA DE MEDICAMENTOS HOMEOPÁTICOS NA FOLICULOGÊNESE INICIAL
}

\section{IN SITU CULTURED PREANTRAL FOLLICLES IS A USEFUL MODEL TO EVALUATE THE EFFECT OF HOMEOPATHY MEDICINE ON EARLY FOLLICULOGENESIS}

\author{
Romão Nunes ${ }^{1}$ \\ Laritza Ferreira de Lima ${ }^{2 *}$ \\ Rebeca Magalhães Pedrosa Rocha \\ Letícia Oliveira $^{1}$ \\ Claudio Cabral Campello ${ }^{2}$ \\ Jose Ricardo Figueiredo ${ }^{2}$ \\ 1Universidade Federal de Goiás, Goiânia, GO, Brasil. \\ 2Universidade Estadual do Ceará, Fortaleza, CE, Brasil. \\ *Autora para correspondência - laritza_lima@yahoo.com.br
}

\section{Resumo}

Este trabalho teve por objetivo avaliar o efeito dos medicamentos homeopáticos (Pulsatilla nigricans e hormônio folículo estimulante homeopático - FSH) e um complexo homeopático (Bos Stress Fertilis) na foliculogênese inicial, utilizando o cultivo in vitro de folículos pré-antrais suínos como modelo in vitro. Para tanto, fragmentos ovarianos foram cultivados por um ou sete dias em $\alpha-\mathrm{MEM}^{+}$ na ausência (controle cultivado) ou presença de FSH homeopático $(6 \mathrm{cH})$, Pulsatilla $(6 \mathrm{CH})$, Bos Stress Fertilis $(6 \mathrm{CH})$, álcool cereal $(50 \%-\mathrm{v} / \mathrm{v})$ ou FSH recombinante $(50 \mathrm{ng} / \mathrm{ml})$ adicionados diariamente. Os fragmentos ovarianos não cultivados (controle fresco) ou cultivados por um e sete dias foram processados para histologia clássica. Somente o composto homeopático Bos Stress Fertilis foi eficiente em manter o percentual de sobrevivência folicular após sete dias de cultivo semelhante ao controle não cultivado e $\alpha-\mathrm{MEM}^{+}$. Em relação ao crescimento folicular, somente a adição de FSH homeopático aumentou o diâmetro folicular quando comparado ao controle não cultivado e $\alpha-\mathrm{MEM}^{+}$ após um dia de cultivo. Dessa forma, pode-se concluir que a adição dos medicamentos homeopáticos Bos Stress fertilis e FSH homeopático $(6 \mathrm{CH})$ melhoraram, respectivamente, a sobrevivência e o crescimento in vitro de folículos pré-antrais suínos inclusos em fragmentos de tecido ovariano.

Palavras-chave: folículo pré-antral; FSH; homeopatia; ovário; suíno.

\footnotetext{
Abstract

This study investigated the effect of homeopathic medicine (Pulsatilla nigricans and homeopathic follicle stimulating hormone - FSH) and the complex (Bos Stress Fertilis) on the initial folliculogenesis, using the in vitro culture of preantral follicles as in vitro model. For this, swine
} 
ovarian fragments were cultured for one or seven days in $\alpha-\mathrm{MEM}^{+}$in the absence (cultured control) or presence of homeopathic FSH $(6 \mathrm{cH})$, Pulsatilla $(6 \mathrm{CH})$, Bos Stress Fertilis $(6 \mathrm{CH})$, grain alcohol $(50 \% \mathrm{v} / \mathrm{v})$ or recombinant FSH $(50 \mathrm{ng} / \mathrm{ml})$ added daily. Uncultured ovarian fragments (fresh control) or cultured for one and seven days were processed for classical histology. Only the homeopathic complex Bos Stress Fertilis maintained the percentage of follicular survival after seven days of culture in relation to the uncultured control and $\alpha-\mathrm{MEM}^{+}$. Regarding follicular growth, only the addition of homeopathic FSH increased the follicular diameter when compared to the uncultured control and a-MEM ${ }^{+}$. Thus, it can be concluded that the addition of the homeopathic remedies Bos Stress fertilis and homeopathic FSH $(6 \mathrm{CH})$ improved, respectively, survival and in vitro growth of swine preantral follicles included in ovarian tissue.

Keywords: FSH; homeopathy; ovary; preantral follicle; swine.

Recebido em: 10 de agosto de 2017

Aceito em:26 de junho de 2018

\section{Introdução}

O tratamento da infertilidade feminina se baseia, principalmente, na administração de medicamentos alopáticos e homeopáticos, os quais podem ser utilizados para tratar problemas relacionados ao desenvolvimento folicular. Embora a alopatia seja a terapia de eleição para curar o paciente, ela possui diversos efeitos indesejáveis ${ }^{(1)}$. Como alternativa a esse problema, muitas mulheres têm optado pelo uso de medicamentos homeopáticos ${ }^{(2)}$ pelo o fato de essa terapia não causar efeitos colaterais.

Os medicamentos homeopáticos vêm sendo usados de forma individual ou associados a outros medicamentos, formando complexos homeopáticos comerciais ${ }^{(3-6)}$. Dentre os medicamentos homeopáticos individuais utilizados no tratamento de infertilidade, temos a Pulsatilla e o FSH homeopático, os quais têm sido administrados para tratar amenorreia ${ }^{(7)}$, promover um ciclo estral mais definido em diversos animais ${ }^{(4,8,9)}$, melhorar o desenvolvimento folicular e tratar cistos foliculares ${ }^{(10)}$. Entretanto, quando se deseja tratar diversos indivíduos ou rebanhos, utilizam-se de diferentes medicamentos homeopáticos reunidos em "complexos", o que possibilita a medicação de populações $^{(11)}$. O Bos Stress Fertilis, por exemplo, é um complexo homeopático utilizado para melhorar a fertilidade em bovinos e tem dados bons resultados, especialmente em propriedades com um bom manejo e em rebanhos em bom estado corporal ${ }^{(12)}$.

Apesar de a homeopatia ser uma ciência antiga e apresentar diversos resultados positivos em estudos in vivo, ela ainda desperta uma série de questões e dúvidas quanto à sua eficiência ${ }^{(13,14)}$. Como forma de contornar tais dúvidas e desvendar o mecanismo de ação de tais medicamentos, sugere-se a utilização de modelos in vitro ${ }^{(15,16)}$, como, por exemplo, o cultivo in vitro de folículos ovarianos.

Utilizando essa biotécnica, nossa equipe conseguiu demonstrar a eficiência da utilização do FSH homeopático (FSH $6 \mathrm{CH}$ ) na manutenção da sobrevivência e promoção da ativação precoce de folículos pré-antrais ovinos inclusos em tecido ovariano ${ }^{(17)}$, atuando de forma semelhante ao FSH recombinante ${ }^{(18)}$. Entretanto, tal teste foi realizado apenas com o FSH homeopático na espécie ovina, sendo necessária a sua ampliação para outros medicamentos homeopáticos bem como testar a sua efetividade em outras espécies incluindo a espécie suína. Desta maneira, este trabalho teve por objetivo avaliar o efeito dos medicamentos homeopáticos (Pulsatilla e FSH $6 \mathrm{CH}$ ) e um complexo 
homeopático (Bos Stress Fertilis $6 \mathrm{CH}$ ) na foliculogênese inicial, utilizando o cultivo in vitro de folículos pré-antrais suínos como modelo in vitro.

\section{Material e Métodos}

Ovários $(\mathrm{n}=10)$ de 5 porcas adultas e não gestantes foram coletados em abatedouro local. Todos os animais eram cíclicos e estavam em boas condições corporais. Imediatamente post-mortem, os ovários foram lavados em álcool $70 \%$ por 10 segundos e então foram lavados em Meio Essencial Mínimo (MEM) suplementado com $100 \mu \mathrm{g} / \mathrm{mL}$ de penicilina e $100 \mu \mathrm{g} / \mathrm{mL}$ de estreptomicina. Os pares de ovários foram transportados ao laboratório em MEM a $33{ }^{\circ} \mathrm{C}$ dentro de duas horas. A menos que indicado de outra forma, os reagentes usados no presente estudo foram adquiridos da Sigma Chemical Co. (St. Louis, MO, USA).

A preparação do $\mathrm{FSH}$ homeopático $(6 \mathrm{CH})$ e Pulsatilla $(6 \mathrm{CH})$ foi realizada na Farmácia Homeopática Naturalis (Fortaleza, CE, Brasil). Para a produção do FSH 6 CH e Pulsatilla 6 CH, foi utilizado $1 \mathrm{~mL}$ do FSH recombinante bovino (Nanocore, Brasil) na concentração de $5 \mathrm{mg} / \mathrm{mL}$ ou $1 \mathrm{~mL}$ do extrato alcoólico da planta Pulsatilla, constituindo assim a tintura mãe de cada medicamento. Depois disso, esses volumes foram diluídos em $99 \mathrm{~mL}$ dos veículos constituídos, respectivamente, por uma solução de álcool cereal a $20 \%$ (v/v) para a confecção do FSH homeopático $(6 \mathrm{CH})$, ou uma solução a $50 \%$ (v/v) para a Pulsatilla. Em seguida, foram realizadas 100 sucussões, constituindo assim a primeira dinamização $(1 \mathrm{cH})$. Posteriormente, $1 \mathrm{~mL}$ da solução dinamizada foi adicionada novamente a $99 \mathrm{~mL}$ do veículo, com o mesmo procedimento de agitação, sendo completada a segunda dinamização (2 $\mathrm{CH}$ ). Foram então realizadas sucussões e diluições até o produto final ficar na sexta dinamização (FSH $6 \mathrm{CH}$ ou Pulsatilla $6 \mathrm{CH}$ ). O Bos Stress Fertilis é um composto homeopático comercial produzido pela Bos Homeopatia Animal Vegetal e Bioterápicos (Goiânia, GO, Brasil), utilizado para reforçar a higidez do ciclo estral e consequentemente obter um cio fértil.

Para o cultivo in situ, ou seja, o cultivo de folículos pré-antrais inclusos em fragmentos de tecido ovariano, o córtex de cada ovário $(\mathrm{n}=10)$ foi dividido em 14 fragmentos de aproximadamente $3 \times 3 \times 1 \mathrm{~mm}$. Dois fragmentos de tecido ovariano tomados aleatoriamente foram fixados em paraformaldeído 4\% tamponado por 12 horas (controle não cultivado) para posterior análise histológica. Os fragmentos restantes foram cultivados individualmente em placas de 24 poços, contendo $1 \mathrm{~mL}$ de meio de cultivo a $39^{\circ} \mathrm{C}$ em uma atmosfera de $5 \% \mathrm{CO}_{2}$ em ar. O meio de cultivo de base, denominado $\alpha-\mathrm{MEM}^{+}$, foi o $\alpha-\operatorname{MEM}(\mathrm{pH}: 7,2-7,4)$ adicionado de $0.1 \%$ de albumina sérica bovina, $10 \mu \mathrm{g} / \mathrm{mL}$ de transferrina e $100 \mu \mathrm{g} / \mathrm{mL}$ de ácido ascórbico. O meio $\alpha-\mathrm{MEM}^{+}$foi suplementado ou não com $50 \mathrm{ng} / \mathrm{mL}$ de FSH recombinante bovino ${ }^{(19)}$, álcool cereal a $50 \%$ (v/v) e substâncias homeopáticas, a saber: FSH homeopático $\left(6 \mathrm{CH}^{17}\right)$, Pulsatilla $(6 \mathrm{CH})$ e Bos Stress Fertilis $(6 \mathrm{CH})$. Os fragmentos ovarianos de cada animal foram cultivados por um ou sete dias. Cada tratamento foi repetido cinco vezes. O meio de cultivo foi estabilizado a $39^{\circ} \mathrm{C}$ por 4 horas antes do uso e foi trocado a cada dois dias.

Imediatamente após a coleta dos ovários, bem como após o término dos períodos de cultivo em cada tratamento, os fragmentos ovarianos foram fixados em paraformaldeído $4 \%$ tamponado por 12 horas e destinados à histologia clássica. Os fragmentos incluídos em blocos de parafina foram seccionados seriadamente à espessura de $7 \mu \mathrm{m}$. Cada quinta secção foi montada em lâmina e corada pelo método do ácido periódico de Schiff (PAS)-hematoxilina. Somente foram analisados os folículos pré-antrais 
cujos oócitos apresentaram o núcleo evidente na secção observada. De acordo com o aspecto qualitativo, os folículos pré-antrais foram classificados como morfologicamente normais ou degenerados, considerando as seguintes características: presença ou ausência de corpos picnóticos, retração citoplasmática e organização das células da granulosa.

A avaliação da ativação e crescimento folicular foi realizada pela quantificação dos folículos nas diferentes classes foliculares de desenvolvimento, enunciadas a seguir: primordial (um oócito circundado por uma camada de células da pré-granulosa pavimentosa), transição (um oócito circundado por células da granulosa pavimentosa e cúbicas), primário (um oócito circundado uma camada de células da granulosa cúbicas) e secundário (um oócito circundado por mais de uma camada de células da granulosa cúbicas) $)^{(20)}$ e por meio de mensuração do diâmetro folicular antes (fragmentos não cultivados) e ao término (fragmentos cultivados) de cada período de cultivo, respectivamente.

Os percentuais de folículos morfologicamente normais, primordiais e em desenvolvimento, após um e sete dias de cultivo, foram inicialmente submetidos ao teste de Smirnov-Kolmogorov e Batlett para confirmar a distribuição normal dos dados e homogeneidade da variância, respectivamente. Análise de variância (ANOVA) foi realizada utilizando o procedimento GLM do SAS (1997), e o teste de Dunnett foi aplicado durante a comparação de cada tratamento testado contra os grupos de controle (controle fresco e $\alpha$-MEM+). O Teste de Student Newman Keuls (SNK) foi utilizado para avaliar os efeitos dos diferentes tratamentos e dias de cultivo com os resultados expressos como média \pm desvio padrão (DP).

\section{Resultados}

Um total de 2.340 folículos pré-antrais foi analisado. As percentagens de folículos pré-antrais morfologicamente normais, em desenvolvimento e o diâmetro folicular no controle (controle não cultivado) e após um ou sete dias de cultivo nos diferentes tratamentos são mostradas na Tabela 1. No dia 7 de cultivo, somente os tratamentos com FSH recombinante, álcool e Bos Stress Fertilis mantiveram a porcentagem de folículos normais em relação ao controle fresco $(\mathrm{P}>0,05)$. Além disso, após sete dias de cultivo, um percentual superior $(\mathrm{P}<0,05)$ de folículos morfologicamente normais foi observado apenas no tratamento com Bos Stress Fertilis, em comparação ao $\alpha$-MEM+ (controle cultivado).

No tocante à ativação folicular, após sete dias de cultivo, exceto no tratamento que continha álcool, houve um aumento significativo no número de folículos em desenvolvimento nos grupos suplementados quando comparado ao controle fresco $(\mathrm{P}<0,05)$. No tocante ao diâmetro folicular, após um dia de cultivo os tratamentos com álcool e FSH homeopático $(6 \mathrm{CH})$ apresentaram para este parâmetro valores significativamente superiores em relação ao controle fresco. Entretanto, nesse mesmo dia, somente o FSH $6 \mathrm{CH}$ promoveu um aumento significativo no diâmetro folicular quando comparado ao $\alpha-\mathrm{MEM}^{+}$. Após sete dias de cultivo, quando comparados todos os tratamentos entre si, o FSH homeopático $(6 \mathrm{CH})$ e a Pulsatilla $(6 \mathrm{CH})$ produziram folículos maiores em relação ao FSH recombinante e ao Bos Stress Fertilis $6 \mathrm{CH}(\mathrm{p}<0,05)$. Vale salientar que, exceto quando comparado ao $\alpha-\mathrm{MEM}^{+}$e ao FSH recombinante, após sete dias de cultivo diâmetros significativamente inferiores foram observados no Bos Stress Fertilis, inclusive em relação ao seu veículo $(\mathrm{p}<0,05)$. Além disso, da mesma forma que para o FSH recombinante, no Bos Stress Fertilis foi observada uma redução significativa do diâmetro folicular do dia 1 para o dia $7(\mathrm{p}<0,05)$. 


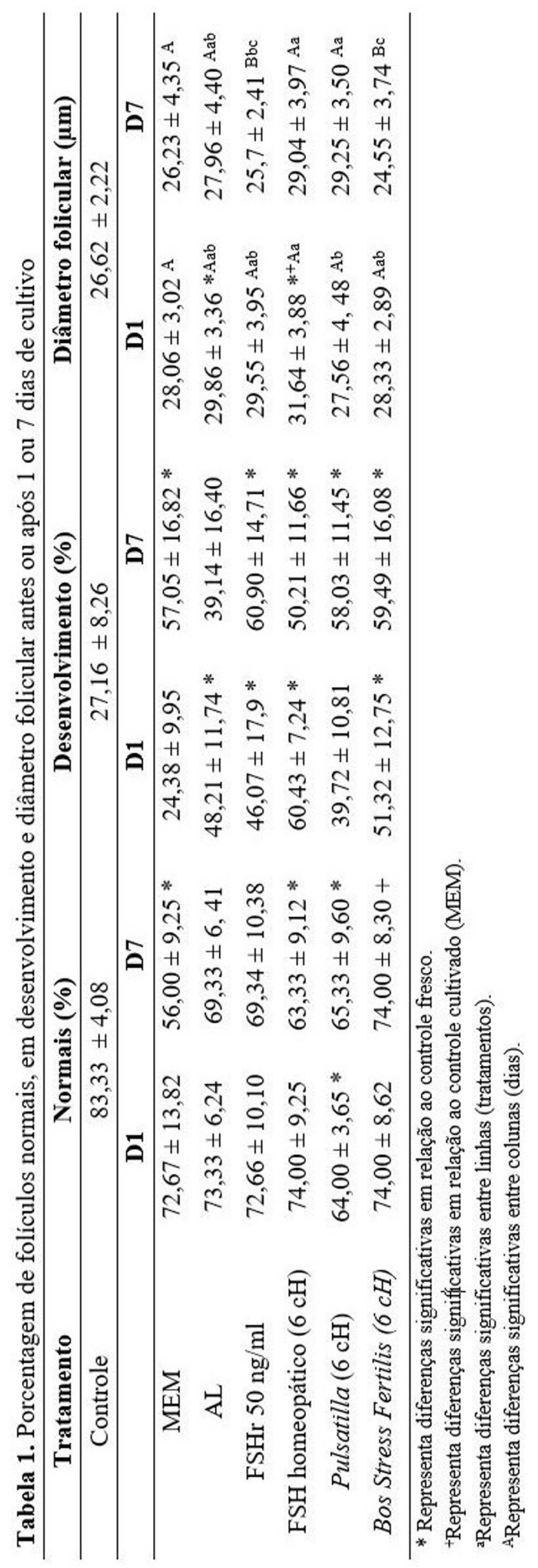




\section{Discussão}

Este estudo avaliou, pela primeira vez, o desenvolvimento in vitro de folículos pré-antrais iniciais inclusos em tecido ovariano de suínos em um cultivo de curta duração (7 dias), utilizando substâncias homeopáticas (FSH 6 CH, Pulsatilla e Bos Stress Fertilis 6 CH) e alopática (FSH na concentração de $50 \mathrm{ng} / \mathrm{mL})$.

O Bos Stress Fertilis, quando utilizado in vivo, é responsável por reforçar a higidez do ciclo estral e, consequentemente, produzir um cio fértil ${ }^{(12)}$. Esse fato pode ser comprovado pelo cultivo in vitro de folículos pré-antrais suínos, uma vez que melhorou, no dia 7 de cultivo, a sobrevivência folicular em relação ao controle cultivado (único tratamento a produzir esse efeito) e promoveu a ativação em relação ao controle fresco. Entretanto, esse composto apresentou diâmetros foliculares inferiores aos outros medicamentos homeopáticos e ao próprio veículo, ao final de sete dias de cultivo. Considerando o fato de esse composto comercial ser uma junção de diversos medicamentos homeopáticos usados para melhorar a fertilidade do gado, é provável que a combinação de alguns medicamentos tenha melhorado a sobrevivência folicular, enquanto existe a possibilidade de essa mesma interação interferir no crescimento. Assim, os efeitos do Bos Stress Fertilis na manutenção da porcentagem de folículos morfologicamente normais em relação ao controle cultivado, a redução no diâmetro folicular comparado ao próprio veículo nesse mesmo tratamento, bem como a ativação após sete dias de cultivo superior ao controle fresco em todos os medicamentos homeopáticos podem indicar um efeito desse composto homeopático sobre o desenvolvimento folicular.

O FSH homeopático $(6 \mathrm{cH})$, neste estudo, atuou melhorando a ativação e o crescimento folicular (dia $1)$ em relação ao controle cultivado $(\alpha-\mathrm{MEM}+)$, sendo o único tratamento que diferiu do controle cultivado em relação ao aumento do diâmetro folicular. Já foi observado o efeito do FSH homeopático em folículos pré-antrais de ovinos na promoção da sobrevivência, ativação e crescimento folicular precoce $^{(17,18)}$. No entanto, no presente estudo não se conseguiu observar um efeito semelhante no tocante ao percentual de folículos morfologicamente normais. Isso ocorreu, provavelmente, devido às diferenças intrínsecas de cada espécie. Além disso, o medicamento homeopático empregado neste estudo, como comprovado em estudos anteriores ${ }^{(17,18)}$, atuou de forma semelhante ao FSH recombinante de origem, não diferindo significativamente do mesmo.

Neste estudo, a Pulsatilla atuou na ativação tardia (efeito observado somente no dia 7 de cultivo), embora tenha aumentado a taxa de degeneração logo após um dia de cultivo em relação ao controle não cultivado. Alguns estudos, utilizando este medicamento in vivo, verificaram que a Pulsatilla 30 e $200 \mathrm{cH}$ atuam de forma semelhante à progesterona no desenvolvimento folicular ${ }^{(21-23)}$, provocando uma redução no peso ovariano, além de uma indução de um elevado número de folículos atrésicos. De forma similar à Pulsatilla, a progesterona aumentou a taxa de degeneração folicular após um e sete dias em caprinos; no entanto, também melhorou a ativação e o crescimento folicular após sete dias de cultivo ${ }^{(24)}$. A progesterona pode agir diretamente aumentando o crescimento folicular ${ }^{(25)}$, ou ainda indiretamente através da sua conversão em testosterona, a qual é convertida para estradiol. Alguns estudos indicam que o estradiol pode promover ativação e crescimento folicular ${ }^{(26,27)}$.

Embora seja visível o efeito desses medicamentos homeopáticos sobre o cultivo in vitro de folículos 
pré-antrais de suínos inclusos em tecido ovariano, ainda não se sabe ao certo por qual via de ação essas substâncias atuam. Acredita-se que a ativação de receptores celulares influenciaria na expressão gênica da célula, promovendo a produção de substâncias endógenas que melhorariam o crescimento folicular ${ }^{(13)}$.

Desta forma, pode-se concluir que os medicamentos homeopáticos FSH $6 \mathrm{CH}$ e Pulsatilla $6 \mathrm{CH}$ atuam na ativação e no crescimento folicular. Enquanto o FSH recombinante $(50 \mathrm{ng} / \mathrm{mL})$ e o Bos Stress Fertilis $6 \mathrm{CH}$ atuam na sobrevivência e ativação de folículos suínos inclusos em tecido ovariano. Além disso, pode-se verificar que o cultivo in vitro de folículos pré-antrais é uma ótima ferramenta para avaliar o potencial de ação dos medicamentos homeopáticos.

\section{Referências}

1. Teixeira MZ. Distúrbios do climatério e tratamento homeopático. Homeopatia Brasileira, 2002;8(1):29-43. 2. Lima LF, Alves AMCV, Rocha RMP, Celestino JJH, Bruno JB, Rodrigues APR, Figueiredo JR. A homeopatia como alternativa no tratamento de distúrbios reprodutivos. Ciência animal, 2012;22(2):25-43.

3. Kumar H, Srivastava SK, Yadav MC, Varshney JP. Management of postpartum anoestrus in dairy animals with a homeopathic combination remedy. Indian Journal of Animal Sciences, 2004;74:739-740.

4. Rajkumar R, Srivastava SK, Yadav MC, Varshney VP, Varshney JP, Kumar H. Effect of a Homeopathic complex on oestrus induction and hormonal profile in anoestrus cows. Homeopathy, 2006;95:131-135.

5. Moreira COC, Costa JFFB, Leal MF, Andrade EF, Rezende AP, Imbeloni AA, Muniz JAPC, Smith MAC, Burbano RR, Assumpção PP. Lymphocyte proliferation stimulated by activated Cebus apella macrophages treated with a complex homeopathic immune response modifiers. Homeopathy, 2012;101:74-79.

6. Deni D, Caminiti A, Lai O, Alfieri L, Casati D, Sciarri M, Scaramozzino P, Brocherel G. Effect of a homeopathic complex on reproductive performance in a commercial pig farm. Homeopathy, 2015;104(1):914.

7. Handley R. Homoeopathy for Women. Thorsens, London, 1993.

8. Silva CTL, Mcmannus C, Runpe R. Efeito da Pulsatilla nigricans aplicada em um ponto de acupuntura na redução do puerpério bovino. Homeopatia Brasileira, 2001;7(1):1 -21.

9. Filho MAR, Bison L. Homeopathic medicines for the treatment of dairy cows with cystic ovarian disease. Brazilian Homeopathic Journal, 2009;11(2):8-13.

10. Legros MS. Utilizacioin de La homeopatìa en endocrinologìa ginecoloìgica. Uso terapeìutico de las hormonas diluidas y dinamizadas. Revista Médica de Homeopatia, 2010;3(1):9-13.

11. Kiefer C, Rizzardi R, Oliveira BF, Silva CM, Martins LP, Fantini CC. Complexo homeopático na prevenção e tratamento de diarréias em leitões lactentes. Revista Brasileira de Saúde e Produção Animal,2012; 13(1):74-82.

12. Bos Homeopatia Animal, Vegetal e Bioterápicos, dados de arquivos, Goiânia, 2014

13. Khuda-Bukhsh AR. Laboratory research in homeopathy: pro. Integrative Cancer Therapies, 2006;5(4):32032, 2006.

14. Bellavite P, Marzotto M, Olioso D, Moratti M, Conforti A. High dilution effects revisited: Pharmacodynamic mechanisms. Homeopathy, 2014;v103:22-43.

15. Preethi K, Ellanghiyil S, Kuttan G, Kuttan R. Induction of apoptosis tumor cells by some potentiated homeopathic drugs: implications of mechanism of action. Integrative Cancer Therapies, 2012;11:172-182.

16. Sikdar S, Saha SK, Khuda-Bukhsh AR. Relative Apoptosis-inducing Potential of Homeopathic Condurango 6C and 30C in H460 Lung Cancer Cells In vitro-Apoptosis-induction by homeopathic Condurango in H460 cells. Journal of Pharmacopuncture, 2014;17(1):059-069.

17. Lima LF, Rocha RMP, Alves AMCV, Saraiva MVA, Araujo VR, Lima IMT, Lopes CAP, Báo SN, 
Campello CC, Rodrigues APR, Figueiredo JR. Dynamized follicle-stimulating hormone affects the development of ovine preantral follicles cultured in vitro. Homeopathy, 2013;102: 41-48.

18. Lima LF, Rocha RMP, Alves AMCV, Carvalho AA, Chaves RN, Lopes CAP, Báo SN, Campello CC, Rodrigues APR, Figueiredo JR. Comparison between the additive effects of diluted (rFSH) and diluted/dynamized (FSH $6 \mathrm{cH}$ ) recombinant follicle-stimulating hormone on the in vitro culture of ovine preantral follicles enclosed in ovarian tissue. Complementary Therapy in Medicine, 2016;25:39-44.

19. Magalhães DM, Araujo VR, Verde IBL, Matos MHT, Silva, R. C.; Lucci, C. M.; BáO, S. N.; Campello, C. C.; Figueiredo, J. R. Different follicle stimulating hormone (FSH) sources influence caprine preantral follicle viability and development in vitro. Pesquisa Veterinária Brasileira, 2009;46(5):378-386.

20. Silva JRV, Van Den Hurk R, Matos MHT, Santos RR, Pessoa C, Moraes MO, Figueiredo JR. Influences of FSH and EGF on primordial follicles during in vitro culture of caprine ovarian cortical tissue. Theriogenology, 2004;61:1691-1704.

21. Chandrasekhar K, Prasad S, Rao CV. Effect of Pulsatilla nigra, a homceopathic drug, on the uteri and estrus cycles in albino rats. Journal of Research in Indian Medicine, Yoga and Homoeopathy, 1976;11(4):48. 22. Prasad S, Chandrasekhar K. Parallel effects of Pulsatilla and exogenous leutocyclin on the rat ovary, uterus and thyroid. British Homeopathic jornal, 1978;67(4):265-275.

23. Rajkumar R, Srivastava SK, Yadav MC, Varshney VP, Varshney JP, Kumar H. Effect of a Homeopathic complex on oestrus induction and hormonal profile in anoestrus cows. Homeopathy, 2006;95:131-135.

24. Lima-Verde IB, Matos MHT, Celestino JJH, Rossetto R, Name KPO, Báo SN, Campello CC, Figueiredo JR. Progesterona e Hormônio Folículo-Estimulante interagem e promovem a sobrevivência e o desenvolvimento in vitro de folículos pré-antrais caprinos. Pesquisa Veterinária Brasileira, 2012;32(4):361367.

25. Peluso JJ, Pappalardo A, Losel R, Wehling M. Progesterone membrane receptor component 1 expression in the immature rat ovary and its role in mediating progesterone's antiapoptotic action. Endocrinology, 2006;147:3133-3140.

26. Murdoch WJ. Inhibition by oestradiol of oxidative stress-induced apoptosis in pig ovarian tissues. Journal of Reproduction and Fertility, 1998;114:127-130.

27. Lima-Verde IB, Matos MHT, Saraiva MVA, Bruno JB, Tenório SB, Martins FS, Rossetto R, Cunha LD, Name KPO, Báo SN, Campello CC, Figueiredo JR. Interaction between Estradiol and Follicle-Stimulating Hormone Promotes in vitro Survival and Development of Caprine Preantral Follicles. Cells Tissues Organs, 2010;191:240-247. 